\title{
An Investigation on the Lead Removal from Soil Contaminated by Mining and Industrial Wastes Using Soapnut in Batch Washing Process
}

\author{
Elijah Chibuzo Ugwu', Bhaskar Sen Gupta ${ }^{1 *}$, Diana Meza-Figueroa², \\ Israel Razo-Soto ${ }^{3}$, Araiza-Reyna Esaú Anybal ${ }^{4}$, Nadia Martínez-Villegas ${ }^{4}$ \\ 1 School of Energy, Geoscience, Infrastructure \&amp; Society, Heriot-Watt University, Water Academy, EGIS \\ 2.02A William Arrol Building, EH14 4AS Scotland, United Kingdom \\ 2 Departamento de Geología, Universidad de Sonora, Rosales y Encinas s/n, Col. Centro, 83000 Hermosillo, \\ Sonora, Mexico \\ 3 Facultad de Ingenieria, Universidad Autónoma de San Luis Potosi, Av. Manuel Nava No. 8, Zona Universitaria, \\ 78290 San Luis Potosi, SLP, Mexico \\ 4 Instituto Potosino de Investigacion Cientifica y Tecnologica, Division de Geociencias Aplicadas, Camino a la \\ Presa San Jose No. 2055, Col. Lomas 4a Sec., 78216 San Luis Potosi, SLP, Mexico \\ * Corresponding author's e-mail: b.sengupta@hw.ac.uk
}

\begin{abstract}
Eco-friendly saponin from soapnut was studied for the remediation of the soils contaminated by lead. This study applied a full factorial design of the experiment with 3 -factors in 3 -level ( $3 \times 3$ factors $)$ to evaluate the effect and interactions of the washing parameters on the lead removal by soapnut in a batch experiment. The parameters studied include: soil-solution ratio, surfactant concentrations by mass, and $\mathrm{pH}$ of the washing solution. Two soil samples representing low lead concentration $(\mathrm{C} 1)$ and high lead concentration $(\mathrm{C} 2)$ were investigated. The findings indicate that the removal efficiency obtained, increases along with the soil-solution ratio and surfactant concentration, but decreases with an increase in the $\mathrm{pH}$ of washing solution. Polynomial models were developed to predict the experimental response and optimal conditions. The model predicted a maximum of 50.54\% and $47.44 \%$ lead removal from the contaminated soil $\mathrm{C} 1$ and $\mathrm{C} 2$, respectively. Multiple washing was investigated using the higher values of the parameters; the responses obtained significantly increased the percentage of lead removed and achieved $79.98 \%$ removal for $\mathrm{C} 1$ and $77.49 \%$ removal for $\mathrm{C} 2$. The effective performance of the soil washing process demonstrates the potential usage of soapnut saponin in the remediation of contaminated soil. Saponin from soapnut is cheap and environment-friendly.
\end{abstract}

Keywords: soapnut; lead; saponin; contaminated soil; soil washing; surfactant

\section{INTRODUCTION}

The soil pollution by poisonous metals has been widely reported in agricultural soils (Järup, 2003, Sharma et al., 2007, Li et al., 2001, Manta et al., 2002, Fakayode and OluOwolabi, 2003, Gäbler and Schneider, 2000, Razo et al., 2004). Human activities, urbanization, and rapid industrialization were linked as the major cause of these pollutions (Wei and Yang, 2010, Cheng, 2003). The incidences of soil contamination around the world are rapidly increasing (Wang and Mulligan, 2004, Qixing, 2002). While the world population has expanded to an estimated figure of 9 billion, there is no corresponding increase in the size of available land. This has made the arable land and clean soil scarce and expensive, as only pristine land can be used for agriculture, property development, wildlife protection and recreational facilities (Hurni, 1996, Morf et al., 2013). Soil pollution also reduces the monetary value of land, 
and makes it unsafe for inhabitation. About one-third of the world's agricultural soils is lost to soil contamination, making them unsuitable for crop production and grazing (Godfray et al., 2010). Therefore, there is an urgent need for efficient remediation technologies to decontaminate soils in order to address this threat. Soil remediation and restoration have also become crucial in achieving the basic human need for safe food and clean water.

Several technologies for the remediation of heavy metal contaminated soils have been developed over the years (Mulligan et al., 2001). These technologies are classified based on two major objectives. The first objective is to immobilize the heavy metals as well as reduce their bioavailability and migration. The second objective is to promote mobility, bioavailability and migration of the heavy metals into the liquid phase for solubilisation and desorption using surface active ingredients known as surfactants. The first technology is not a permanent solution because heavy metals are non-biodegradable, but they can easily transform by sorption, methylation, complexation and changes in the valence state (Hong et al., 2002). The second objective appears to be more promising, as it affords a permanent removal of the metals from soil into the liquid phase where it can be precipitated and recovered (Moon et al., 2015, Shin et al., 2006, Imani et al., 2011, Adeniji, 2004, Hong et al., 2002, Zhou et al., 2013).

The soil washing technologies utilize washing agents to aid in removing contaminants during the washing process. Surfactants are surfaceactive agents that can reduce the surface tension between two liquids or between a liquid and solid. This mechanism causes splitting up and desorption of the hydrophobic compounds and heavy metals using their hydrophobic and hydrophilic properties (Bustamante et al., 2012). The application of surfactants to the soil washing for soil remediation relies on its ability to produce micelles and reduce both the surface and interfacial tension. Surfactants can be produced from both chemical and biological means. The chemical surfactants are known as the synthetic surfactants while the surfactants obtained from plants, animals and microorganisms are called biosurfactants (Soll and Blanco, 2001, Soberón-Chávez and Maier, 2011).

Biosurfactants have been successfully used in soil remediation for both the organic and heavy metal contaminants. Mulligan (2009) reported that the rhamnolipids from pseudomonas aeruginosa have been extensively studied and are produced commercially by Jeneiel Biotech Inc. (Wisconsin). Biosurfactants are easily degradable, environment-friendly and non-toxic. Moreover, they have high specificity, biocompatibility, unique structures, excellent foaming characteristics, and high stability at extreme $\mathrm{pH}$, salinity and temperature, which make them suitable for use in very difficult situationd. These properties have distinguished biosurfactants from the synthetic surfactants giving the former a wider application in industry and environmental remediation efforts (Kobayashi et al., 2012, Lin, 1996, Mulligan, 2009).

Lead is one of the hazardous metals commonly found in mining sites. The soils contaminated with lead can cause serious risk to the human health as well as damage to the environment. Remediation of contaminated soils is targeted at reducing the risk associated with the contaminants and improving the quality of the environment. Saponin, a plant-derived non-ionic biosurfactant is becoming increasingly effective for desorption of metals in the soil washing processes (Hong et al., 2002). Biodegradability, low toxicity, easy recovery and reuse, and potential to improve aqueous dispersion have been identified as the benefits of plant-based saponin (Hong et al., 2002, Kommalapati et al., 1998, Roy et al., 1997). It has also been effective in the solubility improvement of polycyclic aromatic hydrocarbon (PAHs), according to Zhou et al. (2011).

In this study, the efficiency of soapnut (sapindus mukorossi) for the remediation of the contaminated soil in mining areas was investigated. An intensive soil and sediment characterization were carried out in the mining district of Santa Maria del la Paz, located in the municipalities of Villa de la Paz Metehuala in the state of San Luis Potosi (Mexico) by Razo et al. (2004). The study recommended an efficient and environment-friendly remediation approach for the restoration of the contaminated soils and sediments. Various options available for soil remediation have been studied worldwide, but soil washing using biosurfactants seems to be the most effective, environmentfriendly and a feasible solution for removing metals from the contaminated soil (Venkatesh and Vedaraman, 2012, Maity et al., 2013a). 


\section{MATERIALS AND METHODS}

\section{Soil sample collection}

The soil samples used in this study were contaminated as a result of historical and recent mining activities at various locations of Villa de la Paz-Matehuala, San Luis Potosi (Mexico). The sampling was designed to collect the real contaminated soil samples to remove the lead content using natural surfactants. Extensive sampling was carried out from a total of $105 \mathrm{~km}^{2}$ study area to further select 8 sampling sites to represent a range of lead contamination. The sampling locations are shown in Figure 1. Two samples were selected to represent the high and low contaminated soils. The sampling points included urban areas, school playgrounds and agricultural land.

\section{Soil physicochemical analysis}

The collected samples were dried at room temperature $\left(<35^{\circ} \mathrm{C}\right)$ on plastic trays at a layer less than $2.5 \mathrm{~cm}$ thick. Subsequently, the air dried samples were homogenized and sieved through $2 \mathrm{~mm}$ screen (10 mesh). Soil characterization was done to determine various physical and chemical properties of the soil sample in-situ and in the laboratory. The soil moisture content was determined in-situ with HSM50 precision digital soil moisture meter. The data were recorded in triplicate, according to the values read from the LCD display of the meter. The organic matter content was determined by weight loss on ignition method (ASTM D 2974). The soil $\mathrm{pH}$ and electrical conductivity (EC) were measured with the slurry method according to Official Mexican Standard NOM-021-SEMARNAT-2000

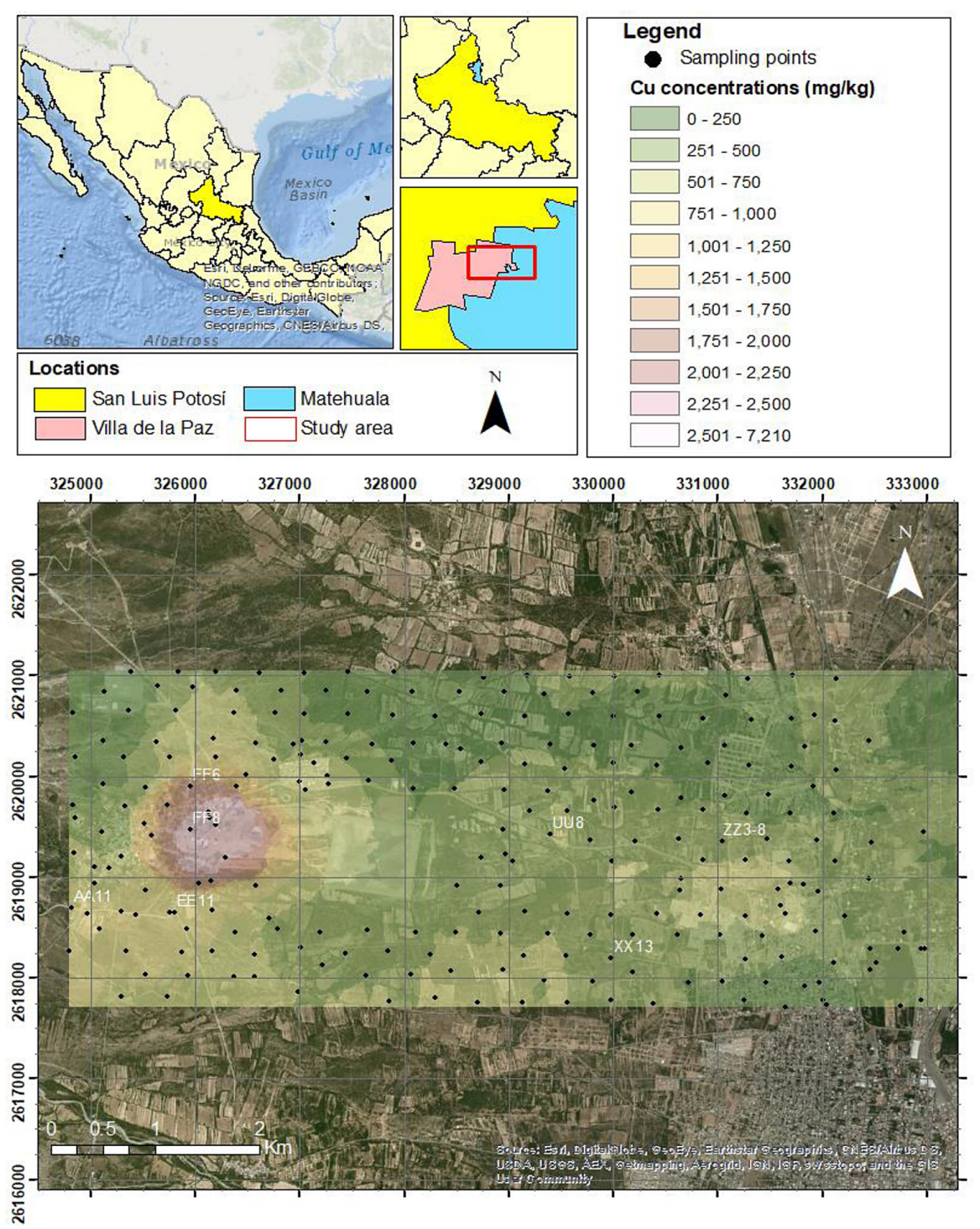

Figure 1. The map showing corresponding to spatial distribution for Lead and sampling points used for the experiments 
(DOF, 2002). Cation exchange capacity (CEC) was determined by sodium acetate following the method 9081 (Chapman, 1965). XRD analysis was performed to identify the mineralogical components of the soil using a Bruker D8 advance X-ray diffractometer fitter with a $\mathrm{Cu} \mathrm{K} \alpha$ source. Total metal analysis was performed using X-ray fluorescence spectrometry (XRF) according to Environmental Protection Agency (EPA) Method 6200 (Hseu et al., 2016).These physicochemical properties are shown in Table 1 and Figure 2.

\section{Preparation of plant based surfactant}

The soapnut (Sapindus mukorossi) powder procured from Davis Finest production, Hampshire, UK was used in this study as surfactant. In order to prepare $10 \%$ stock solution of the washing fluid, $10 \mathrm{~g}$ of pure dry organic soapnut powder was added to $100 \mathrm{ml}$ of distilled water. The solution was thoroughly mixed for about $3 \mathrm{hr}$ at room temperature before being centrifuged at $3000 \mathrm{rpm}$ for $25 \mathrm{~min}$ and then filtered before being diluted to the desired concentration following a modification of similar procedures (Zhang et al., 1998). The washing solutions were used freshly without storage.

\section{Surfactant characterization}

The surfactant used in this study was characterized in terms of the surface tension, molecular structure and $\mathrm{pH}$. The surface tension and critical micelle concentrations (CMC) were measured by pendant drop experiment using Theta Lite contact angle goniometer. With a syringe, a sessile drop of the liquid was formed and placed at the film surface. Image recording started before the drop touched the surface by a camera coupled to the goniometer. The surface tension and CMC were calculated by the Young-Laplace equation using the OneAttension control software. Readings were repeated for ten times, the results were copied to Microsoft Excel, and the mean and standard deviation were calculated. The molecular structure of the surfactant was characterized before and after washing using Fourier transform infrared spectroscope (FTIR). This was meant to test if there was any chemical interaction between the soil and the surfactant and also to assess the process causing the removal of metals from the soil. The $\mathrm{pH}$ of the surfactant was determined for each concentration used. The results for surfactant characterization are shown in Table 2.

\section{Experimental design and statistical analysis}

Preliminary investigation was conducted to help screen out some factors, which were not necessary for the effective experiments. Essential factors were used to conduct the second phase of the experiments, which are kinetic and full factorial design. All experiments were conducted in triplicate and the average values were reported. The statistical analysis was carried out using

Table 1. Physiochemical properties of soils used for the experiments

\begin{tabular}{|c|c|c|c|}
\hline \multirow{2}{*}{ Soil properties } & \multicolumn{2}{|c|}{ Values } & \multirow{2}{*}{ Method } \\
\hline & $\mathrm{C} 1$ & $\mathrm{C} 2$ & \\
\hline $\mathrm{pH}$ & 7.45 & 7.30 & \multirow{3}{*}{ NOM-021-SEMARNAT-2000 } \\
\hline Electrical conductivity $(\mathrm{dS} / \mathrm{m})$ & 0.18 & 0.12 & \\
\hline Soil moisture content $(\%)$ & 7.1 & 12.0 & \\
\hline Soil CEC (meq) & 2.15 & 1.50 & Sodium acetate method 9081 \\
\hline Organic matter content & 19.0 & 6.3 & Ignition method (ASTM D 2974) \\
\hline Particle size distribution & Sandy-loam & Loam & \multirow{4}{*}{ NOM-021-SEMARNAT-2000 } \\
\hline Silt & 40 & 46 & \\
\hline Sand & 56.04 & 42.04 & \\
\hline Clay & 3.96 & 11.96 & \\
\hline Lead $(\mathrm{mg} / \mathrm{kg})$ & 1345 & 287 & \multirow{8}{*}{ EPA Method 6200 (USEPA 2007) } \\
\hline Arsenic (mg/kg) & 1050 & 519 & \\
\hline Copper (mg/kg) & 400 & 1616 & \\
\hline Zinc (mg/kg) & 2129 & 761 & \\
\hline Iron $(\mathrm{mg} / \mathrm{kg})$ & 241200 & 21185 & \\
\hline Potassium (mg/kg) & 12094 & 7327 & \\
\hline Calcium (mg/kg) & 162617 & 276210 & \\
\hline Manganese $(\mathrm{mg} / \mathrm{kg})$ & 1106.43 & 412 & \\
\hline
\end{tabular}



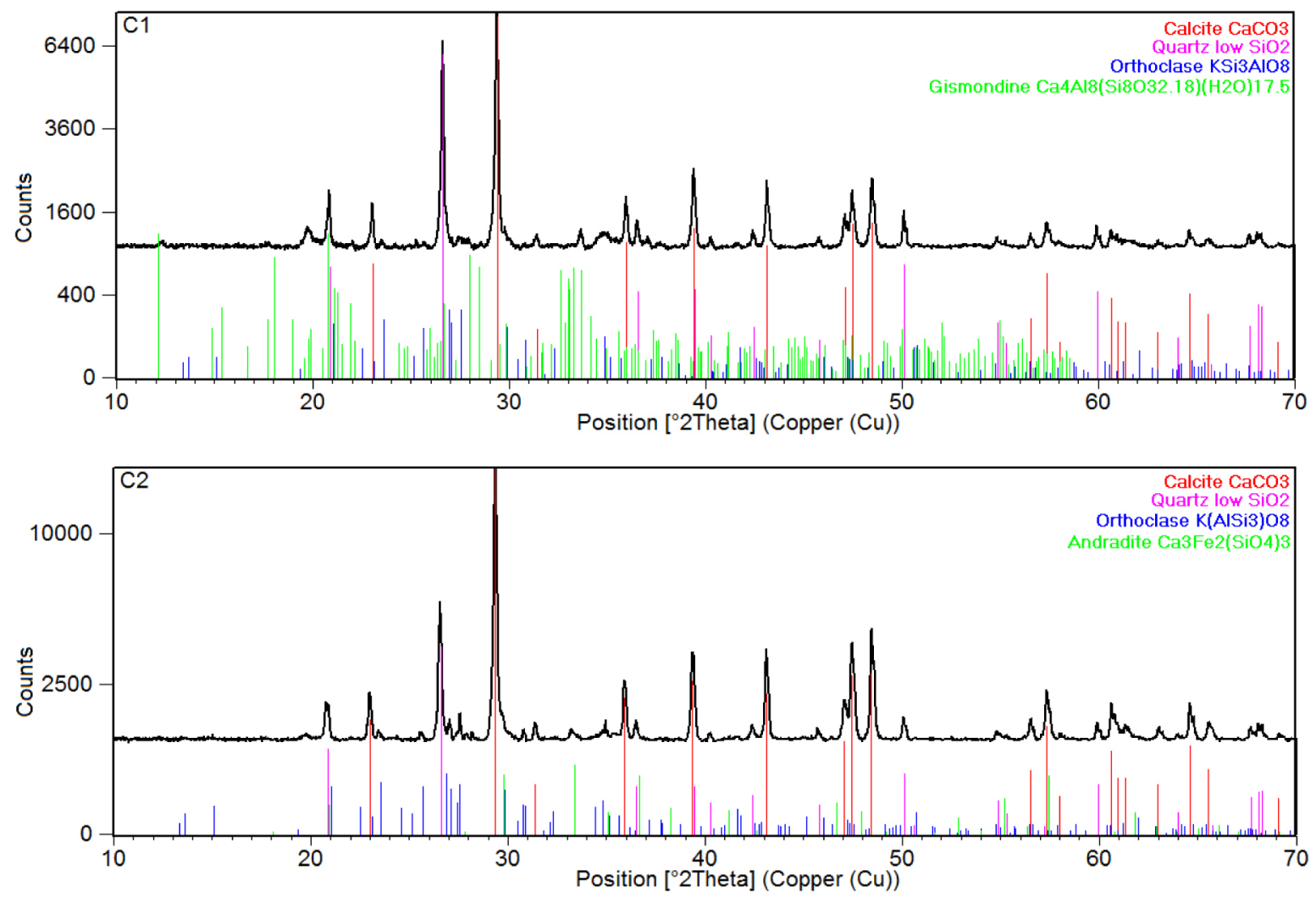

Figure 2. XRD spectra showing various counts of minerals components of the soils used in the study $\mathrm{C} 1$ is the soil with high $\mathrm{Pb}$ contamination $(1345 \mathrm{mg} / \mathrm{kg})$, while $\mathrm{C} 2$ is the soil with low $\mathrm{Pb}$ contamination $(287 \mathrm{mg} / \mathrm{kg})$

Table 2. Characterization of surfactant and deionized water used for soil washing experiments

\begin{tabular}{|c|c|c|c|c|c|c|}
\hline Surfactant & Empirical formula & Mol. Wt & CMC & $\begin{array}{l}\text { Conc. } \\
\text { used }\end{array}$ & Surface tension & $\mathrm{pH}$ \\
\hline $\begin{array}{c}\text { Deionized } \\
\text { water }\end{array}$ & $\mathrm{H}_{2} \mathrm{O}$ & 18 & & & $73.56 \pm 0.95$ & $5.74 \pm 0.23$ \\
\hline \multirow{4}{*}{ Soapnut } & \multirow{4}{*}{$\mathrm{C}_{52} \mathrm{H}_{84} \mathrm{O}_{21} \cdot 2 \mathrm{H}_{2} \mathrm{O}$} & \multirow{4}{*}{$1,081.24$} & \multirow{4}{*}{$0.1 \%$} & $1 \%$ & $36.96 \pm 0.89$ & $4.33 \pm 0.09$ \\
\hline & & & & $2 \%$ & $34.91 \pm 0.57$ & $4.29 \pm 0.56$ \\
\hline & & & & $3 \%$ & $34.50 \pm 0.37$ & $4.25 \pm 0.09$ \\
\hline & & & & $4 \%$ & $34.29 \pm 0.51$ & $4.23 \pm 0.23$ \\
\hline
\end{tabular}

analysis of variance (ANOVA) followed by the Ttest at 0.05 and 0.01 , significance levels. The data summary and calculations were performed using Microsoft Excel and Minitab, and the graphs were drawn using Origin software.

\section{Soil washing experiments}

Batch extractions were conducted in laboratory scale to investigate the effect of surfactant concentrations, soil solution ratio and $\mathrm{pH}$ of the washing solution. The batch tests were conducted in $125 \mathrm{ml}$ conical flask over a rotary shaker at about $200 \mathrm{rpm}$ for a given contact time at room temperature $\left(24^{\circ} \mathrm{C}\right)$. The $\mathrm{pH}$ of the surfactant solution was increased or reduced accordingly by the addition of hydrochloric acid or sodium hydroxide (Mulligan et al., 1999b). The supernatants were collected and filtered using a Whatman filter paper after centrifuging at $9000 \mathrm{~g}$ for $15 \mathrm{~min}$ (Luna et al., 2016). A drop of nitric acid was usually added to the samples for preservation and stored for inductively coupled plasma optical emission spectroscopy (ICP-OES) analysis. The response was usually recorded as percentage of lead removed and calculation was done by using a similar equation as that reported by (Wuana et al., 2010):

Percentage of lead removal $=\frac{C_{1} V_{1}}{C_{S} M_{S}} 100 \%$ where: $C_{1}(\mathrm{mg} / \mathrm{l})$ and $C_{S}(\mathrm{mg} / \mathrm{kg})$, are the concentrations of metal in supernatant and soil respectively; $V_{1}$ is the volume of supernatant (l); $M_{S}$ is the dry mass of the soil (kg). 
The $\mathrm{pH}$ of the solution was recorded before washing and after washing in supernatant. In order to ensure precision, all the experiments were performed in replicate and results were presented as averages of the replication values (Zou et al., 2009).

\section{Multiple washing}

Three series of batch washings were conducted using optimum conditions from the full factorial design. The optimum experimental conditions used were $\mathrm{pH} 4$, soil-solution ratio 1:100 and surfactant concentrations of $6 \%$. The procedures given in section 2.5 were followed for the batch experiment and, at each setup of multiple soil washing, fresh saponin solution was added to each poly-ethylene tube. The $\mathrm{Pb}$ removal was determined after every wash using Equation 1.

\section{Kinetic study}

Kinetic studies were conducted to test the rate of desorption of lead over time. According to (Zou et al., 2009), metal desorption from soil is a kinetic process, and, therefore, extraction time plays an important role in soil washing. A method similar to the one used by (Mukhopadhyay et al., 2015) was used to conduct the experiments. Five grams of contaminated soil were shaken with 100 $\mathrm{ml}$ of soapnut solution at a $5 \%$ concentration in a $250 \mathrm{ml}$ conical flask. The $\mathrm{pH}$ of the surfactant solution was adjusted to 4 , and the test was run at: 0 , $0.5,1.0,1.5,2.0,2.5,3.0,3.5,4.0,6.0,8.0,24.0$, and 48.0 hours. The removal of lead from the soil was estimated at each time interval by collecting $5 \mathrm{ml}$ samples, which were later filtered and preserved by adding 1 drop of nitric acid and stored for ICP-OES analysis.

\section{RESULTS AND DISCUSSIONS}

\section{Soil characterisation}

The soils used in this study were predominantly calcite calcium carbonate $\left(\mathrm{CaCO}_{3}\right)$ with associating minerals (see Fig. 2). Soil with high $\mathrm{Pb}$ contamination $(\mathrm{C} 1)$ has Calcite $\mathrm{CaCO}_{3}(35 \%)$, Brushite $\mathrm{KaHPO}_{4}\left(\mathrm{H}_{2} \mathrm{O}\right)_{2}(23 \%)$, Quartz low $\mathrm{SiO}_{2}$ $(30 \%)$, Cristobalite $\mathrm{SiO}_{2}(1 \%)$ and Orthoclase $\mathrm{K}_{0.94} \mathrm{Na}_{0.06}\left(\mathrm{AlSi}_{3} \mathrm{O}_{8}\right)(11 \%)$. The soil with low $\mathrm{Pb}$ contamination (C2) has Calcite $\mathrm{CaCO}_{3}(62 \%)$,
Quartz alfha $\mathrm{SiO}_{2}(22 \%)$, Orthoclase $\mathrm{K}\left(\mathrm{AlSi}_{3} \mathrm{O}_{8}\right)$ (9\%), and Andradite $\mathrm{Ca}_{3} \mathrm{Fe}_{2}\left(\mathrm{SiO}_{4}\right)_{3}$ (4\%). The higher level of arsenic and heavy metals content in soil (C1) may be due to high organic matter content which has been reported to have great affinity for metal binding (Zeng et al., 2011, Micó et al., 2006, Maity et al., 2013a). Table 2 shows the results related to the physiochemical properties of the soils used in the experiments. The $\mathrm{pH}$ of the soil which is slightly neutral favours the existence of plants and living organisms, although at lower $\mathrm{pH}$, the removal of metal from soil is enhanced. Electrical conductivity (EC) measures the level of salinity in the soil. High EC is known to have adverse effect on the survival of plant and microorganisms in the soil. The EC value of 0.18 is essential and $0.12 \mathrm{dS} / \mathrm{m}$ is within the non-saline range of soil. Soil C1, has high organic matter content which makes it rich for crop production and microbial activities. CEC measures the capacity of soil to allow for exchange of cations. The sources of CEC in the soils are clay and organic matter. The CEC obtained from the two soils are generally low. Generally, the low values of EC and CEC in the soils used for this experiments means that the soil was permeable and will enhance leachability of metals by soil washing (Wuana et al., 2010, Sarubbo et al., 2015).

\section{Surfactant characterization}

\section{pH and surface tension of the washing solutions}

Table 3 shows the results of the $\mathrm{pH}$ and the surface tension of the deionized water and soapnut used in this study. The deionized water has a low $\mathrm{pH}$ compare to pure water due to carbon dioxide dissolution from the atmosphere. The results of surface tension show that the natural surfactant used is capable of lowering the surface tension even at the lower concentration (1\%). The $\mathrm{pH}$ of the surfactant at various concentrations indicates that the surfactant is a weak acid. According to (Kommalapati et al., 1998) the saponin has a critical micelles concentration of $1000 \mathrm{mg} / \mathrm{l}$ and $10 \%$ solution has an equivalent total organic carbon value of $41 \mathrm{~g} / 1$.

\section{FT-IR spectral data of soapnut before and after to washing}

FT-IR (Thermo Nicolet modlo 6700) spectra of aqueous soapnut are shown in Figure 3, where we can observe the differences between 
Table 3. Full factorial design matrix with the experimental response and predicted values for the removal of $\mathrm{Pb}$ from contaminated soil $\mathrm{C} 1$ and $\mathrm{C} 2$

\begin{tabular}{|c|c|c|c|c|c|c|c|}
\hline \multicolumn{4}{|c|}{ Independent variables } & \multicolumn{4}{|c|}{$(\%)$ removal of $\mathrm{Pb}$ from soil $(\mathrm{C} 1)$} \\
\hline \multirow{2}{*}{$\mathrm{S} / \mathrm{N}$} & \multirow{2}{*}{$\mathrm{pH}$} & \multirow{2}{*}{$\begin{array}{l}\text { Soil-solution } \\
\text { ratio (SSR) }\end{array}$} & \multirow{2}{*}{$\begin{array}{l}\text { Concentration } \\
\text { (Conc.) }\end{array}$} & \multicolumn{2}{|c|}{ C1 } & \multicolumn{2}{|c|}{$\mathrm{C} 2$} \\
\hline & & & & Observed & Predicted & Observed & Predicted \\
\hline 1 & 4 & 20 & 0 & 0.19 & 2.50 & 0.17 & 2.50 \\
\hline 2 & 5 & 20 & 0 & 0.16 & 1.95 & 0.12 & 1.76 \\
\hline 3 & 6 & 20 & 0 & 0.12 & 1.40 & 0.09 & 1.01 \\
\hline 4 & 4 & 20 & 2 & 13.72 & 9.10 & 12.32 & 8.51 \\
\hline 5 & 5 & 20 & 2 & 8.28 & 7.01 & 7.48 & 6.27 \\
\hline 6 & 6 & 20 & 2 & 6.86 & 4.91 & 5.26 & 4.02 \\
\hline 7 & 4 & 20 & 4 & 22.92 & 22.31 & 21.22 & 20.53 \\
\hline 8 & 5 & 20 & 4 & 16.25 & 17.12 & 13.85 & 15.29 \\
\hline 9 & 6 & 20 & 4 & 12.75 & 11.93 & 11.25 & 10.05 \\
\hline 10 & 4 & 60 & 0 & 1.11 & 5.63 & 1.11 & 5.22 \\
\hline 11 & 5 & 60 & 0 & 1.12 & 4.37 & 1.12 & 3.97 \\
\hline 12 & 6 & 60 & 0 & 0.51 & 3.10 & 0.51 & 2.73 \\
\hline 13 & 4 & 60 & 2 & 21.65 & 15.99 & 20.95 & 14.81 \\
\hline 14 & 5 & 60 & 2 & 18.40 & 13.28 & 17.80 & 12.23 \\
\hline 15 & 6 & 60 & 2 & 15.76 & 10.67 & 13.86 & 9.65 \\
\hline 16 & 4 & 60 & 4 & 31.62 & 36.43 & 30.32 & 33.99 \\
\hline 17 & 5 & 60 & 4 & 27.49 & 31.11 & 24.39 & 28.75 \\
\hline 18 & 6 & 60 & 4 & 22.57 & 25.79 & 21.17 & 23.50 \\
\hline 19 & 4 & 100 & 0 & 1.55 & 8.77 & 1.15 & 7.93 \\
\hline 20 & 5 & 100 & 0 & 0.92 & 6.79 & 0.90 & 6.19 \\
\hline 21 & 6 & 100 & 0 & 0.68 & 4.81 & 0.58 & 4.44 \\
\hline 22 & 4 & 100 & 2 & 33.81 & 22.70 & 31.01 & 21.10 \\
\hline 23 & 5 & 100 & 2 & 28.72 & 19.56 & 26.02 & 18.19 \\
\hline 24 & 6 & 100 & 2 & 21.77 & 16.42 & 20.37 & 15.28 \\
\hline 25 & 4 & 100 & 4 & 48.43 & 50.54 & 44.93 & 47.44 \\
\hline 26 & 5 & 100 & 4 & 42.71 & 45.10 & 40.89 & 42.20 \\
\hline 27 & 6 & 100 & 4 & 38.78 & 39.65 & 35.71 & 36.96 \\
\hline
\end{tabular}

the transmittance spectra for soapnut solutions, together with the absorption range of different molecular vibrations, such as the phenolic-OH bond located at $3315 \mathrm{~cm}^{-1}$ and the $\mathrm{C}=\mathrm{C}$ stretching located at $1638 \mathrm{~cm}^{-1}$ which indicate the presence of alkene groups. Similar observations were reported by Pradhan and Bhargava, (2008) in another study. In these results, it can be observed that there is no displacement of the peaks in the FT-IR spectrum between the soapnut solution before and after being used to wash contaminated soils C1 and C2. FTIR of the solutions collected after soil washing showed no apparent changes in the spectra, which would indicate that there was no chemical interaction between the saponin and soil throughout the washing process (Figure 3).

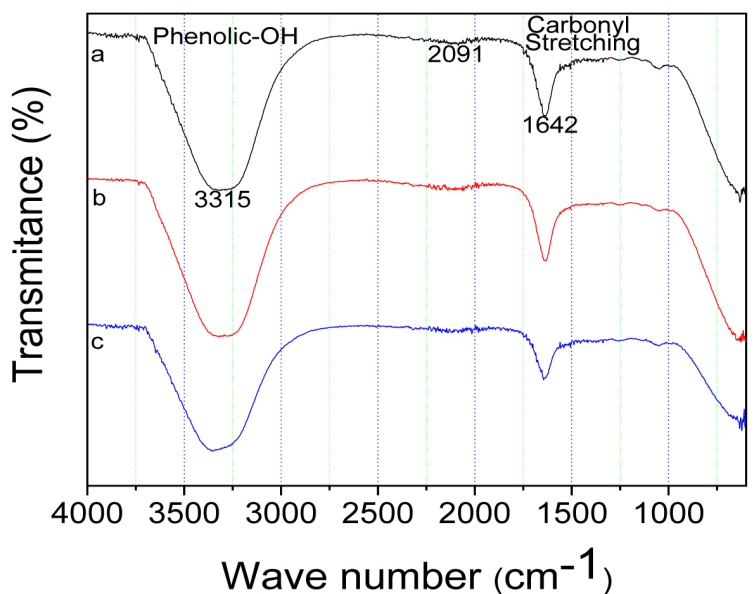

Figure 3. FTIR: a) soapnut before washing, (b) soapnut after washing soil $\mathrm{C} 1,(\mathrm{c})$ soapnut after washing soil C2 


\section{Soil washing experiments}

\section{Screening experiments}

The results from the screening experiment (Graeco-Latin square not shown) established that the surfactant concentration has the highest influence in lead removal efficiency, against time of reaction, contaminant concentration and $\mathrm{pH}$ of the surfactant concentration. The response was recorded for the removal efficiency in the batch washing test using Equation 1. The removal efficiency obtained from the full factorial design ranged from $0.08 \%$ to $1.5 \%$ for deionized water and $6.86 \%$ to $48.43 \%$ for soapnut saponin solution, as shown in Table 3. The highest removal efficiency was obtained at the surfactant concentration of $4 \%, \mathrm{pH}$ of 4 and soil-solution ratio of 1:100. Low removal efficiency obtained at single washing generally depicts the strong binding of $\mathrm{Pb}$ to the soil, and the fact that metals are strongly adsorbed on contaminated soil, making them very difficult to remediate (Sarubbo et al., 2015). Generally, the $\mathrm{Pb}$ removal increases along with the saponin concentration and soil-solution ratio but decreases with an increase in the $\mathrm{pH}$ of washing solution. The same trend was reported by Zhou et al. (2013) in the study of enhanced soil washing of phenanthrene by a plant-derived natural surfactant. Furthermore, Maity et al. (2013a) reported an increase in the removal efficiency of nickel (Ni) and Manganese $(\mathrm{Mn})$ when the surfactant concentration increased from 0.015 to $0.150 \mathrm{~g} / \mathrm{l}$. Hong et al. (2002) also reported a higher removal efficiency of saponin at the concentration of $3 \%$ and at $\mathrm{pH}$ of 3 . In this study, the surfactant concentration and soil solution ratio were the main factors influencing the removal efficiency.

\section{Development of regression model equation using full factorial design}

A full factorial design with 3-factor and 3-level was applied to evaluate the mutual effects of three independent variables, including $\mathrm{pH}$, Soilsolution ratio (SSR), and surfactant concentration (Conc.), on the lead removal efficiencies of soapnut from the contaminated soil $\mathrm{C} 1$ and $\mathrm{C} 2$. The second-order polynomial regression equations were generated by the Minitab 18 software to describe the lead removal efficiencies. The equations are expressed in uncoded forms, as shown in Eqns. 2 and 3:

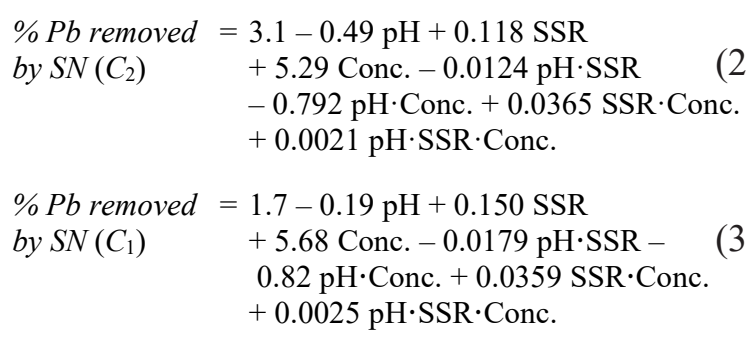

The experimental design and details along with the response values as well as predicted values are shown in Table 3. The relationships between the predicted values and experimental responses (Fig. 4) show that the developed quadratic models demonstrate proper fitting to the lead removal efficiency for the experimental data. The model predicted a maximum removal of $50.54 \%$ as against $48.43 \%$ observed response for the contaminated soil C1. Similarly, the model predicted $47.44 \% \mathrm{~Pb}$ removal from the contaminated soil $\mathrm{C} 2$ as against $44.93 \%$ observed from the experiment. The normal probability plot of residual values and the Pareto plots are not shown.

\section{ANOVA analysis for lead removal from contaminated soils (C1 and C2) using soapnut}

The results of experiments were analysed in Minitab and presented in ANOVA Tables 4 and 5. The model terms of the ANOVA for all the experiments were significant $(\mathrm{P}<0.05)$. The ANOVA tables indicate that there were strong interaction between the surfactant concentration and the soilsolution ratio, and the $\mathrm{pH}$ of the washing solution. The surfactant concentration and soil-solution ratio were significant in all the experiments. This was similar to the findings of the preliminary experiments, which showed that the surfactant concentration was a major controlling factor.

The squared regression R-sq and adjusted $\mathrm{R}$-sq are strong indication of a reliable fit of the model to the experimental data and its usefulness in predicting the responses. In this study, high values of R-sq were recorded in the range of $89.96 \%$ to $90.37 \%$. The range for adj R-sq was from $86.26 .71 \%$ to $86.82 \%$. The predicted R-sq values were in the range of $80.74 \%$ to $81.05 \%$. The $\mathrm{S}$ values were between 4.98 to 5.42. The low value of S and high values of R-sq, adjusted R-sq and predicted R-sq suggested a good fit of the model to the experimental data. In general, there is strong evidence that the model is adequate to fit the data and predict the response (Venkatesh and Vedaraman, 2012). 


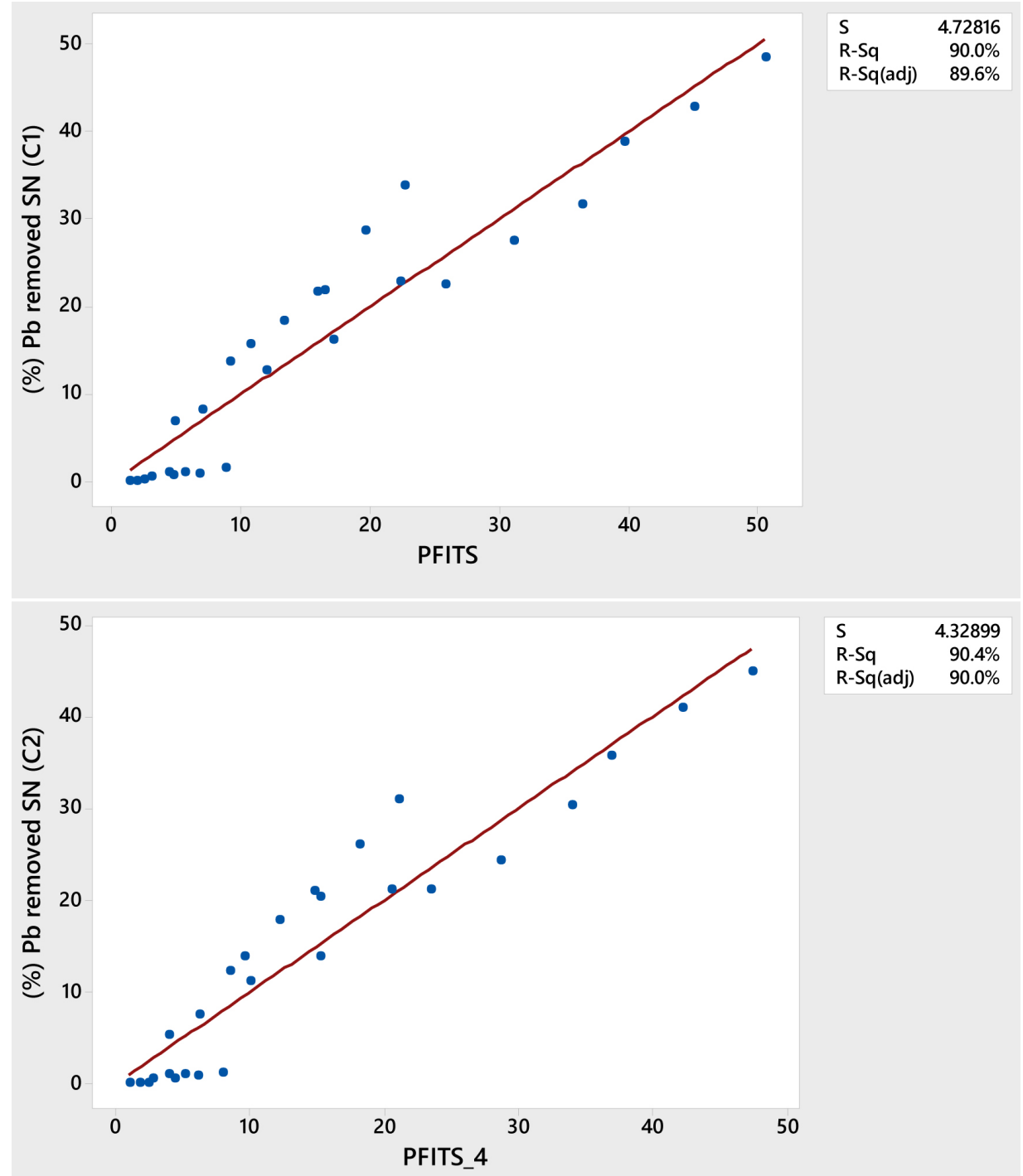

Figure 4. Predicted values of percentage $\mathrm{Pb}$ removal from contaminated soil $\mathrm{C} 1$ versus actual values (PFITS is the predicted values)

Table 4. Analysis of variance for $\mathrm{Pb}$ removal by soapnut from contaminated soil (C1)

\begin{tabular}{|c|c|c|c|c|c|}
\hline Source & DF & Adj SS & Adj MS & F-Value & P-Value \\
\hline Model & 7 & 5006.49 & 715.21 & 24.31 & 0.000 \\
\hline Linear & 3 & 4719.53 & 1573.18 & 53.48 & 0.000 \\
\hline $\mathrm{pH}$ & 1 & 191.61 & 191.61 & 6.51 & 0.019 \\
\hline SSR & 1 & 1190.47 & 1190.47 & 40.47 & 0.000 \\
\hline Conc. & 1 & 3337.45 & 3337.45 & 113.46 & 0.000 \\
\hline 2-Way Interactions & 3 & 469.29 & 156.43 & 5.32 & 0.008 \\
\hline $\mathrm{pH}^{*} \mathrm{SSR}$ & 1 & 2.10 & 2.10 & 0.07 & 0.792 \\
\hline $\mathrm{pH}^{*}$ Conc. & 1 & 51.03 & 51.03 & 1.73 & 0.203 \\
\hline SSR*Conc. & 1 & 416.16 & 416.16 & 14.15 & 0.001 \\
\hline 3-Way Interactions & 1 & 0.72 & 0.72 & 0.02 & 0.878 \\
\hline $\mathrm{pH}^{\star} \mathrm{SSR}^{\star}$ Conc. & 1 & 0.72 & 0.72 & 0.02 & 0.878 \\
\hline Error & 19 & 558.89 & 29.42 & & \\
\hline Total & 26 & 5565.38 & & & \\
\hline \multicolumn{6}{|l|}{ Model Summary } \\
\hline $\mathrm{S}$ & & 5.42 & & & \\
\hline R-sq & & $89.96 \%$ & & & \\
\hline R-sq(adj) & & $86.26 \%$ & & & \\
\hline R-sq(pred) & & $80.74 \%$ & & & \\
\hline
\end{tabular}


Table 4 illustrates the ANOVA of $\mathrm{Pb}$ removed by soapnut from the contaminated soil $\mathrm{C} 1$. It can be observed from the Table 4 that the model term, the $\mathrm{pH}$, soil-solution ratio, and surfactant concentration are all significant $(\mathrm{P}<0.05)$. The 2-way interactions of the model are significant; the 2-way interactions of soil-solution ratio and surfactant concentration are also significant. The 2-way interactions between the $\mathrm{pH}$ and surfactant concentrations as well as $\mathrm{pH}$ and soil-solution ratio were not significant. Moreover, the 3-way interactions of the model and parameters were not significant. The model summary shows that the values of S, R-sq, R-sq (adj) and R-sq (pred) are 5.42\%, $89.96 \%, 86.26 .765 \%$ and $80.74 \%$ respectively.

Table 5 illustrates the ANOVA of $\mathrm{Pb}$ removed by soapnut from the contaminated soil $\mathrm{C} 2$. It can be observed from the Table 5 that the model term, the $\mathrm{pH}$, soil-solution ratio, and surfactant concentration are all significant $(\mathrm{P}<0.05)$. The 2 -way interactions of the model are significant; the 2-way interactions of soil-solution ratio and surfactant concentration are also significant. The 2-way interactions between the $\mathrm{pH}$ and surfactant concentrations as well as $\mathrm{pH}$ and the soil-solution ratio were not significant. Moreover, the 3-way interactions of the model and that of the 3 parameters were not significant. The model summary shows that the values of S, R-sq, R-sq (adj) and R-sq (pred) are $4.97 \%, 90.37 \%, 86.82 \%$ and $81.05 \%$ respectively.

\section{Effect of surfactant concentration}

The effect of soapnut concentration on the removal of lead from the contaminated soil is expressed as the removal efficiency in percentage. In this study, the soapnut concentrations were investigated in $3 \times 3$ full factorial experiments. Three values of the concentration were tested, which include deionized water ( $0 \%$ surfactant) and $2 \%$, and $4 \%$ of the soapnut saponin solution. Figs. 5 and 6 , show the effects of surfactant concentration on the removal efficiencies observed for soapnut for the contaminated soils, $\mathrm{C} 1$ and $\mathrm{C} 2$. The results of the batch experiments show that the removal efficiency increases along with the concentration of surfactant.

This was shown by the ANOVA results that the surfactant concentrations were significant. Deionized water can only obtain a maximum removal efficiency of $1.5 \%$ showing that these metals are strongly bonded to the soil. Again, it shows that unlike saponin, which can reduce the surface tension of liquid and form micelles, deionized water cannot form micelles or complexes with metals that could hold the lead under suspension. Therefore deionized water is not as effective as in soil washing (Mukhopadhyay et al., 2015). The importance of washing with deionized water is to show the evidence of fractions of metals that is weakly bound to the contaminated soil and can be

Table 5. Analysis of variance for $\mathrm{Pb}$ removed by soapnut from contaminated soil (C2)

\begin{tabular}{|c|c|c|c|c|c|}
\hline Source & DF & Adj SS & Adj MS & F-Value & P-Value \\
\hline Model & 7 & 4416.09 & 630.87 & 25.47 & 0.000 \\
\hline Linear & 3 & 4143.14 & 1381.05 & 55.75 & 0.000 \\
\hline $\mathrm{pH}$ & 1 & 185.57 & 185.57 & 7.49 & 0.013 \\
\hline SSR & 1 & 1085.73 & 1085.73 & 43.83 & 0.000 \\
\hline Conc. & 1 & 2871.84 & 2871.84 & 115.93 & 0.000 \\
\hline 2-Way Interactions & 3 & 443.74 & 147.91 & 5.97 & 0.005 \\
\hline $\mathrm{pH}^{*} \mathrm{SSR}$ & 1 & 0.73 & 0.73 & 0.03 & 0.865 \\
\hline $\mathrm{pH}^{\star}$ Conc. & 1 & 49.98 & 49.98 & 2.02 & 0.172 \\
\hline SSR ${ }^{\star}$ Conc. & 1 & 393.03 & 393.03 & 15.87 & 0.001 \\
\hline 3-Way Interactions & 1 & 0.51 & 0.51 & 0.02 & 0.887 \\
\hline $\mathrm{pH}^{*} \mathrm{SSR}^{*}$ Conc. & 1 & 0.51 & 0.51 & 0.02 & 0.887 \\
\hline Error & 19 & 470.65 & 24.77 & & \\
\hline Total & 26 & 4886.74 & & & \\
\hline \multicolumn{6}{|l|}{ Model Summary } \\
\hline$S$ & & 4.98 & & & \\
\hline R-sq & & $90.37 \%$ & & & \\
\hline R-sq(adj) & & $86.82 \%$ & & & \\
\hline R-sq(pred) & & $81.05 \%$ & & & \\
\hline
\end{tabular}




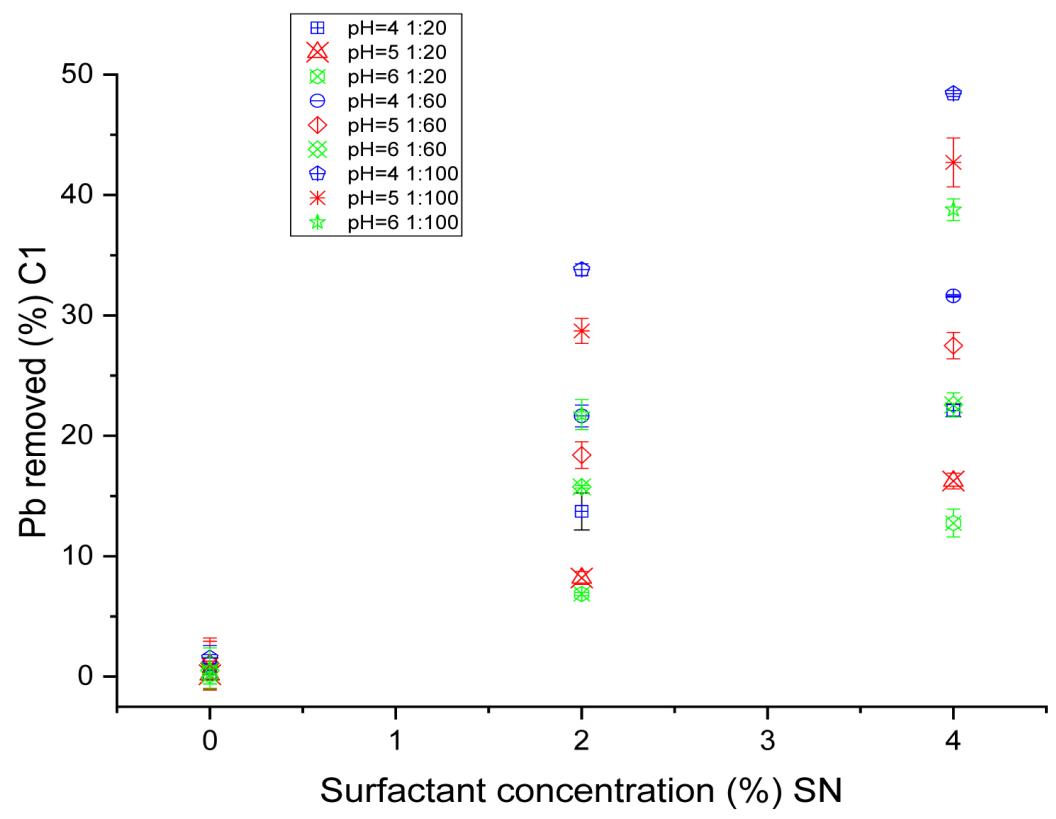

Figure 5. Effect of soapnut concentration on the removal $\mathrm{Pb}$ from contaminated soil $(\mathrm{C} 1)$

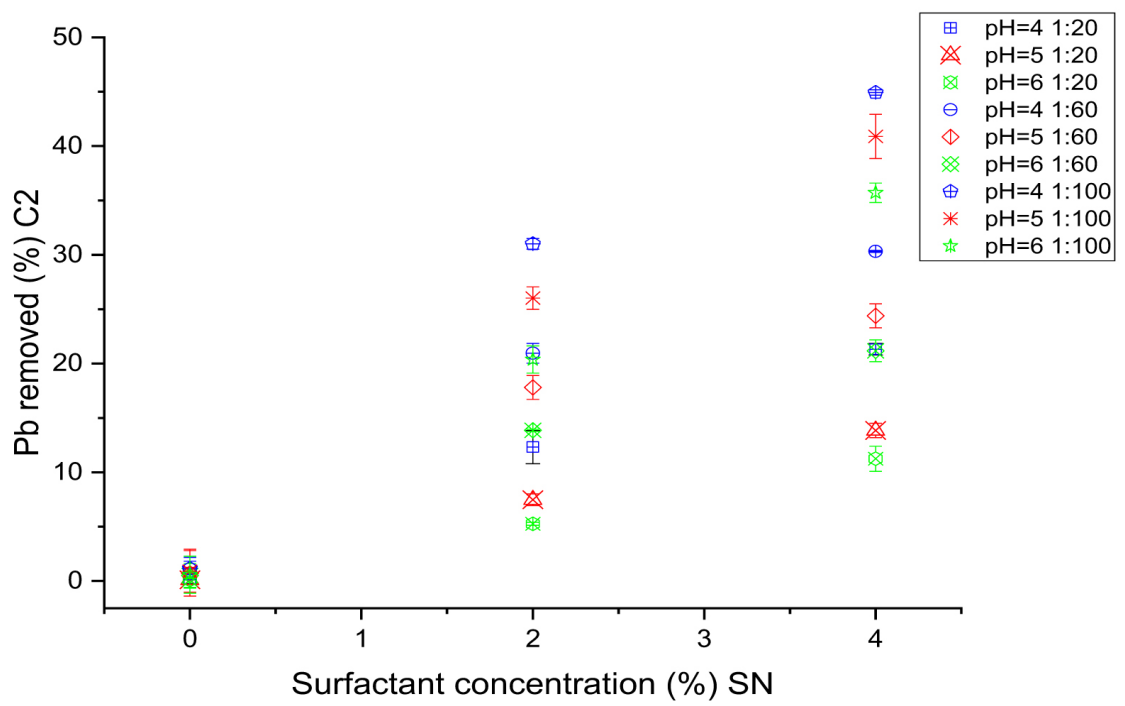

Figure 6. Effect of soapnut concentration on the removal $\mathrm{Pb}$ from contaminated soil $(\mathrm{C} 2)$

easily mobilized (Abumaizar and Smith, 1999). In this study, the poor performance of deionized water shown in the cumulative removal efficiency is an evidence of strong bond existing between the contaminated soil and the lead contaminant. Moreover, real soils from the contaminated sites are very difficult to remediate, especially if they have been contaminated for a long period of time (Chang et al., 2010). The lowest surfactant concentration of $2 \%$ produced the lowest lead removal, which could indicate that higher surfactant concentrations are more effective for lead removal, as reported in previous studies (Maity et al., 2013a, Mukhopadhyay et al., 2015).

\section{Effect of $\mathrm{pH}$}

Electrostatic attraction between saponin and the soil surface determines the amount of saponin sorbed onto soils, and this amount increases with a decrease in $\mathrm{pH}$ (Açıkel, 2011, Hong et al., 2002). The $\mathrm{pH}$ is an essential factor that determines the extent of metal desorption. The $\mathrm{pH}$ of washing solution influences the amount of saponin adsorbed onto the soil that influences the extent of metal desorption from soil. It is also important in the formation of complexes and keeping the desorbed metals in suspension (Zou et al., 2009, Aç1kel, 2011, Hong et al., 2002). 
Effect of $\mathrm{pH}$ was tested in this study by performing experiments at $\mathrm{pH} \mathrm{4,5}$ and 6 . In general, higher desorption of lead was obtained at $\mathrm{pH} 4$, as shown in Figs. 7 and 8. The removal efficiency increased with a decrease in the $\mathrm{pH}$ of the washing solution and decreased with an increase in the $\mathrm{pH}$. At $\mathrm{pH} 4$, the lead removal efficiency reached its highest values with other parameters, namely, $4 \%$ surfactant concentration and 1:100 soil-solution ratio. This result is in agreement with the report of Hong et al. (2002) and Maity et al. (2013b) in which the highest removal efficiencies were obtained at lower $\mathrm{pH}$. It is worth noting that the $\mathrm{pH}$ of the surfactant solution was the least significant factor among the three factors considered in this study. Although $\mathrm{pH}$ played great role in metal desorption, other factors such as: contaminant nature, surfactant concentration, soil-solution ratio and time of reaction can exert greater influence in soil washing.

\section{Effect of soil-solution ratio}

The effect of soil-solution ratio on the removal of $\mathrm{Pb}$ was investigated in this study by varying the volume of saponin solution and the mass of the contaminated soils at three different ratios: 1:20, 1:60 and 1:100. From the results of the experiments shown in Figs. 9 and 10, it can be seen that there was a positive effect on the $\mathrm{Pb}$ removal efficiency as the increase in the

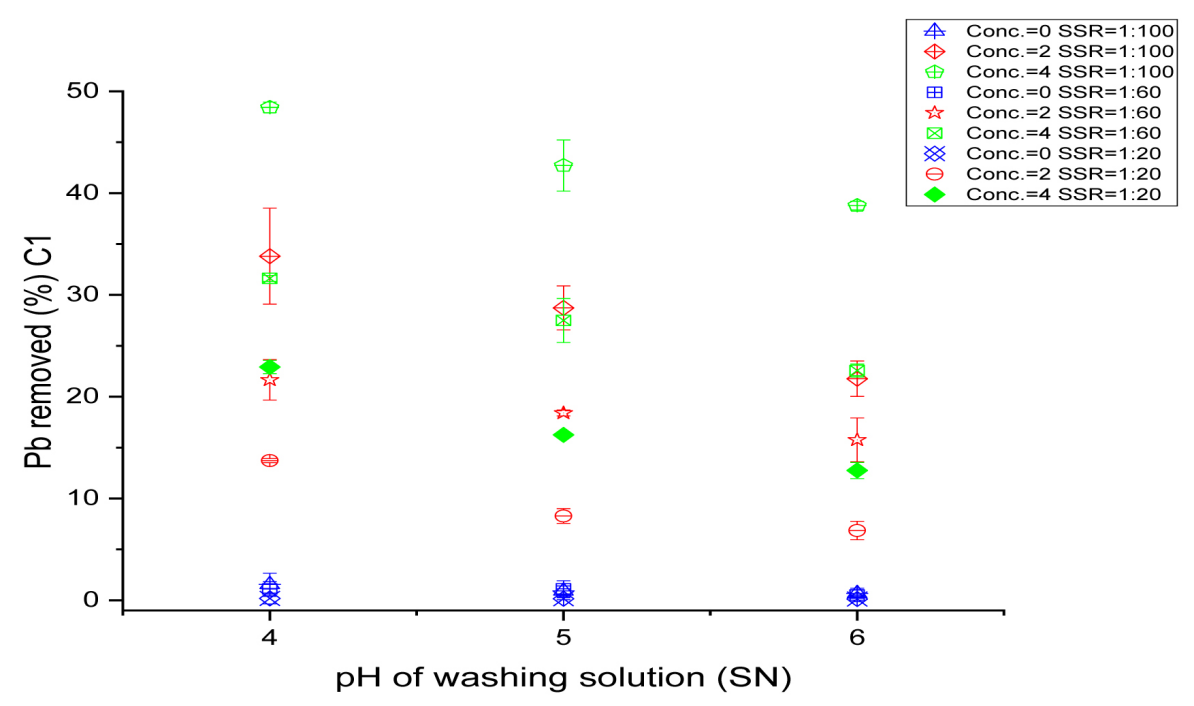

Figure 7. Effect of soapnut $\mathrm{pH}$ on the removal of $\mathrm{Pb}$ from contaminated soil (C1)

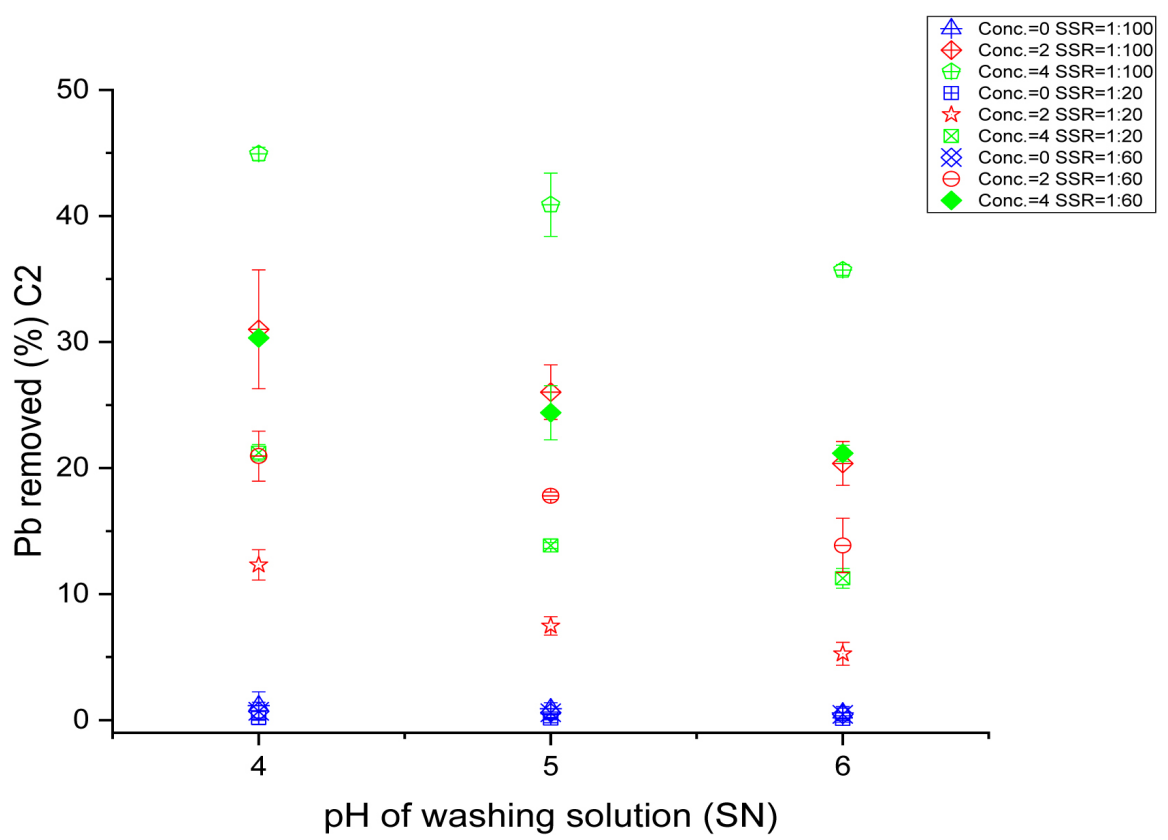

Figure 8. Effect of soapnut $\mathrm{pH}$ on the removal of $\mathrm{Pb}$ from contaminated soil (C2) 


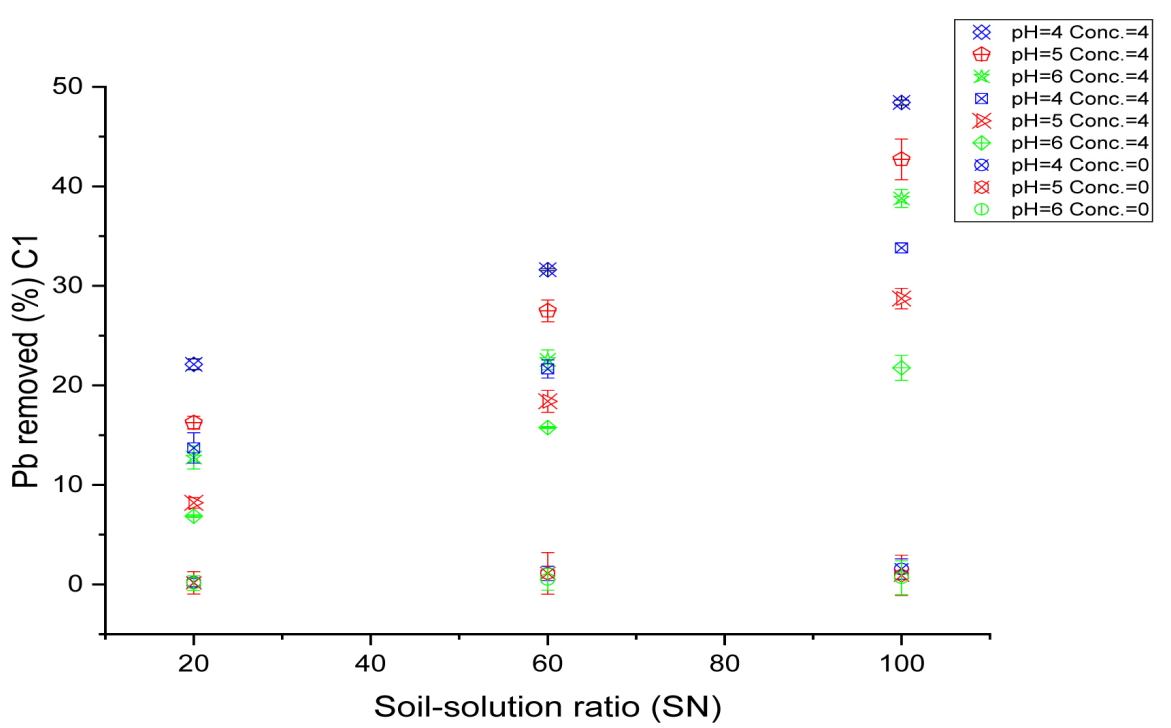

Figure 9. Effect of soapnut soil-solution ratio on the removal of $\mathrm{Pb}$ from contaminated soil $(\mathrm{C} 1)$

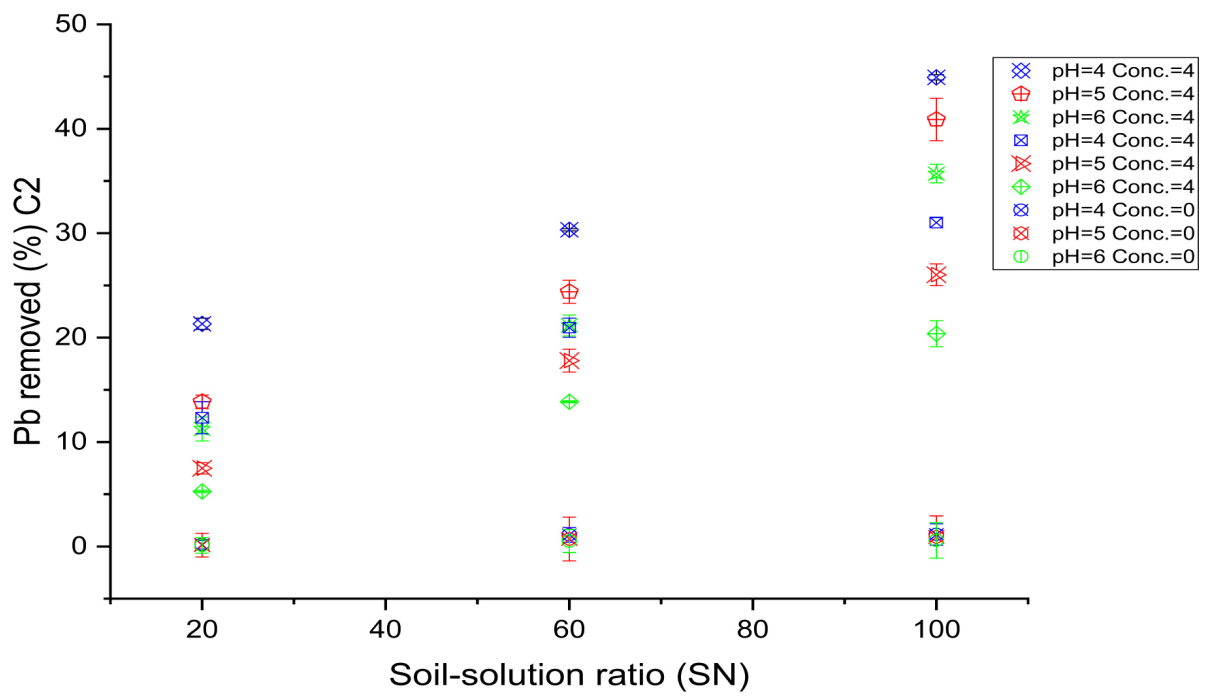

Figure 10. Effect of soapnut soil-solution ratio on the removal of $\mathrm{Pb}$ from contaminated soil (C2)

soil-solution ratio resulted in an increase in the amount of $\mathrm{Pb}$ removed. At a ratio of 1:100, high removal efficiencies were obtained for all the experiments carried out. Previous studies (Zou et al., 2009, Mukhopadhyay et al., 2015), reported similar increase with higher soil-solution ratios. Zou et al. (2009) suggested using a higher soilsolution ratio, rather than increasing the concentration of the washing solution.

With an increase in the soil-solution ratio, more saponin molecules will be added to the washing solution and more micelles will be formed. This would facilitate the saponin complex formation with metals promoting remediation of soils (Franzetti et al., 2014). In this study, the soil-solution ratio was statistically significant in all the ANOVA for the experiments. There was a significant difference between the $\mathrm{Pb}$ removed at ratio 1:20, 1:60 and 1:100. Previous studies (Zou et al., 2009, Mukhopadhyay et al., 2015), reported similar results. The major reason for studying the influence of the soil-solution ratio is to determine the right amount of the washing solution that will be sufficient to remove the toxic metals from a known quantity of contaminated soil. This is essential for the adequate planning and determination of the operational cost for remediation. In the laboratory scale, this study can help in the modelling and determining the optimum values of the operating variables for satisfactory remediation of a known quantity of contaminated soil.

\section{Influence of multiple washing}

Although single extraction could remove $\mathrm{Pb}$ from the contaminated soil, the removal 


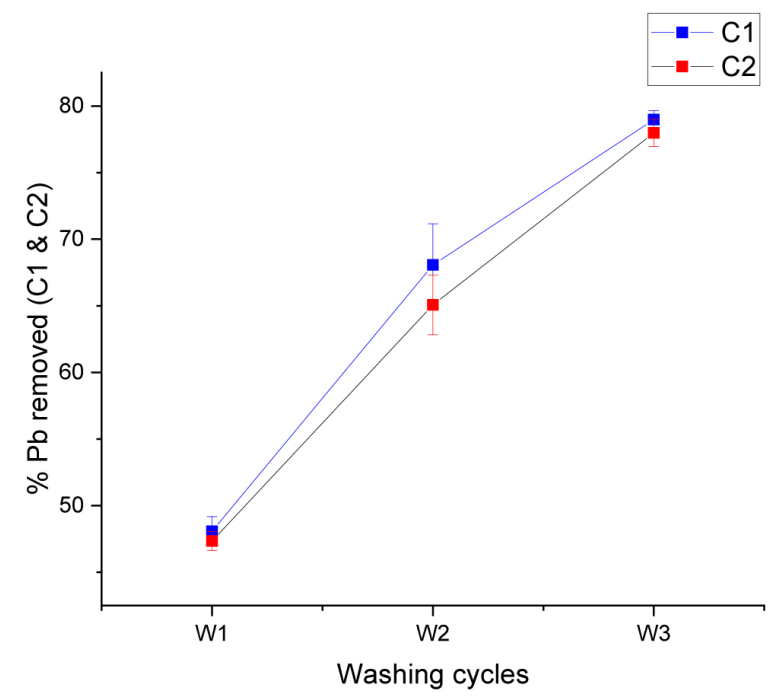

Figure 11. The cumulative percentage of $\mathrm{Pb}$ removed from contaminated soils $\mathrm{C} 1$ and $\mathrm{C} 2$ after triple washings

efficiency by one washing may not be enough to clean-up the contaminated soil. Multiple washing may be more suitable for complete remediation of the contaminated soil (Zou et al., 2009). Mulligan et al. (1999a) performed a series of washings in a bid to clean-up heavy metals from the oil-contaminated soil using biosurfactants. Gusiatin and Klimiuk (2012) studied the removal of copper, cadmium and zinc using multiple washing and stabilization with the help of saponin. Multiple washing was performed in this study to increase the removal efficiency obtained during a single washing. Three series of batch washings were conducted using selected values. These values are $\mathrm{pH} 4$, soil-solution ratio 1:100 and saponin concentration of $4 \%$. After each wash, fresh saponin solution of the same concentration was added to each poly-ethylene tube.

Figure 11 shows the cumulative removal efficiency obtained after three washings of $\mathrm{C} 1$ and $\mathrm{C} 2$ contaminated soil. It indicates that soapnut saponin removed a cumulative of $79.98 \%$ of $\mathrm{Pb}$ from the contaminated soil $\mathrm{C} 1$ while the cumulative of $77.48 \%$ was removed from the contaminated soil $\mathrm{C} 2$ after triple washing cycles.

\section{CONCLUSION}

The feasibility of using eco-friendly biodegradable saponin to remove the mining and industrial polluted soil was studied. Saponin from soapnut, a plant-based surfactant was investigated for its effectiveness as cleaning agent. The washing parameters studied include: soil-solution ratio, surfactant concentration and $\mathrm{pH}$ of the washing solution. The response was measured as the removal efficiency. There was a significant level of influence of the factors studied on the removal efficiency. An increase in the concentration of surfactant and soil-solution ratio resulted in an increase in the removal efficiency, while a decrease in $\mathrm{pH}$ of washing solution brought an increase in the $\mathrm{Pb}$ removed from the soil.

A single wash of the contaminated soil with soapnut solution could remove up to $48 \%$ of lead from the contaminated soil. The performance of multiple washing significantly increased the amount of $\mathrm{Pb}$ removed and higher removal efficiencies were recorded. The general performance of the washing liquid indicates that the soapnut utilization in soil washing can be effective and can compete favourably with commonly used chemical reagent. Moreover, the overall performance of the soil washing process demonstrates the potential usage of soapnut saponin in soil remediation of the contaminated soil. Saponin from soapnut is relatively cheap and environment-friendly, compared with the chemical washing agents.

\section{REFERENCES}

1. Abumaizar, R.J. \& Smith, E.H. 1999. Heavy metal contaminants removal by soil washing. Journal of Hazardous Materials, 70, 71-86.

2. Adeniji, A. 2004. Bioremediation of arsenic, chromium, lead, and mercury. National network of enviromental management studies fellow for US Enviromental Protection Agency Office of Solid Waste and Emergency Response Technology Innovation Office. Washington, DC.

3. Açikel, Y.S. 2011. Use of biosurfactants in the removal of heavy metal ions from soils. Biomanagement of metal-contaminated soils. Springer.

4. Bustamante, M., Duran, N. \& Diez, M. 2012. Biosurfactants are useful tools for the bioremediation of contaminated soil: A review. Journal of Soil Science and Plant Nutrition, 12, 667-687.

5. Chang, J.-H., Shi, Y.-H. \& Tung, C.-H. 2010. Stepwise addition of chemical reagents for enhancing electrokinetic removal of cu from real site contaminated soils. Journal of Applied Electrochemistry, 40, 1153-1160.

6. Cheng, S. 2003. Heavy metal pollution in China: origin, pattern and control. Environmental Science and Pollution Research, 10, 192-198. 
7. Fakayode, S.O. \& Olu-Owolabi, B. 2003. Heavy metal contamination of roadside topsoil in Osogbo, Nigeria: Its relationship to traffic density and proximity to highways. Environmental Geology, 44, 150-157.

8. Franzetti, A., Gandolfi, I., Fracchia, L., Van Hamme, J., Gkorezis, P., Marchant, R. \& Banat, I.M. 2014. Biosurfactant Use in Heavy Metal Removal from Industrial Effluents and Contaminated Sites. Biosurfactants: Production and Utilization-Processes, Technologies, and Economics, 361.

9. Godfray, H.C.J., Beddington, J.R., Crute, I.R., Haddad, L., Lawrence, D., Muir, J.F., Pretty, J., Robinson, S., Thomas, S.M. \& Toulmin, C. 2010. Food security: the challenge of feeding 9 billion people. science, 327, 812-818.

10. Gusiatin, Z.M. \& Klimiuk, E. 2012. Metal (Cu, $\mathrm{Cd}$ and $\mathrm{Zn}$ ) removal and stabilization during multiple soil washing by saponin. Chemosphere, 86, 383-391.

11. Gäbler, H.-E. \& Schneider, J. 2000. Assessment of heavy-metal contamination of floodplain soils due to mining and mineral processing in the Harz Mountains, Germany. Environmental Geology, 39, 774-782.

12. Hong, K.-J., Tokunaga, S. \& Kajiuchi, T. 2002. Evaluation of remediation process with plant-derived biosurfactant for recovery of heavy metals from contaminated soils. Chemosphere, 49, 379-387.

13. Hseu, Z.-Y., Chen, Z.-S., Tsai, C.-C. \& Jien, S.-H. 2016. Portable X-ray fluorescence (pXRF) for determining $\mathrm{Cr}$ and $\mathrm{Ni}$ contents of serpentine soils in the field. Digital Soil Morphometrics. Springer.

14. Hurni, H. 1996. Precious earth: from soil and water conservation to sustainable land management, Centre for Development and Environment (CDE); Geographica Bernensia.

15. Imani, S., Rezaei-Zarchi, S., Hashemi, M., Borna, H., Javid, A. \& Abarghouei, H.B. 2011. Hg, Cd and $\mathrm{Pb}$ heavy metal bioremediation by Dunaliella alga. Journal of Medicinal Plants Research, 5, 2775-2780.

16. Järup, L. 2003. Hazards of heavy metal contamination. British medical bulletin, 68, 167-182.

17. Kobayashi, T., Kaminaga, H., Navarro, R.R. \& Iimura, Y. 2012. Application of aqueous saponin on the remediation of polycyclic aromatic hydrocarbonscontaminated soil. Journal of Environmental Science \& Health, Part A: Toxic/Hazardous Substances \& Environmental Engineering, 47, 1138-1145.

18. Kommalapati, R.R., Valsaraj, K.T., Constant, W.D. \& Roy, D. 1998. Soil flushing using colloidal gas aphron suspensions generated from a plant-based surfactant. Journal of Hazardous Materials, 60, 73-87.

19. Li, X., Poon, C.-S. \& Liu, P. S. 2001. Heavy metal contamination of urban soils and street dusts in Hong Kong. Applied geochemistry, 16, 1361-1368.
20. Lin, S.C. 1996. Biosurfactants: recent advances. Journal of Chemical Technology and Biotechnology, 66, 109-120.

21. Luna, J.M., Rufino, R.D. \& Sarubbo, L.A. 2016. Biosurfactant from Candida sphaerica UCP0995 exhibiting heavy metal remediation properties. Process Safety and Environmental Protection.

22. Maity, J.P., Huang, Y.M., Fan, C.-W., Chen, C.-C., Li, C.-Y., Hsu, C.-M., Chang, Y.-F., Wu, C.-I., Chen, C.-Y. \& Jean, J.-S. 2013a. Evaluation of remediation process with soapberry derived saponin for removal of heavy metals from contaminated soils in Hai$\mathrm{Pu}$, Taiwan. Journal of Environmental Sciences, 25, 1180-1185.

23. Maity, J.P., Huang, Y. M., Hsu, C.-M., Wu, C.-I., Chen, C.-C., Li, C.-Y., Jean, J.-S., Chang, Y.-F. \& Chen, C.-Y. 2013b. Removal of $\mathrm{Cu}, \mathrm{Pb}$ and $\mathrm{Zn}$ by foam fractionation and a soil washing process from contaminated industrial soils using soapberry-derived saponin: a comparative effectiveness assessment. Chemosphere, 92, 1286-1293.

24. Manta, D.S., Angelone, M., Bellanca, A., Neri, R. \& Sprovieri, M. 2002. Heavy metals in urban soils: a case study from the city of Palermo (Sicily), Italy. Science of the Total Environment, 300, 229-243.

25. Micó, C., Recatalá, L., Peris, M. \& Sánchez, J. 2006. Assessing heavy metal sources in agricultural soils of an European Mediterranean area by multivariate analysis. Chemosphere, 65, 863-872.

26. Moon, D., Jo, R., Koutsospyros, A., Cheong, K. \& Park, J.-H. 2015. Soil Washing of Fluorine Contaminated Soil Using Various Washing Solutions. Bulletin of Environmental Contamination \& Toxicology, 94, 334.

27. Morf, L.S., Gloor, R., Haag, O., Haupt, M., Skutan, S., Di Lorenzo, F. \& Böni, D. 2013. Precious metals and rare earth elements in municipal solid wastesources and fate in a Swiss incineration plant. Waste Management, 33, 634-644.

28. Mukhopadhyay, S., Hashim, M., Allen, M. \& Gupta, B.S. 2015. Arsenic removal from soil with high iron content using a natural surfactant and phosphate. International Journal of Environmental Science and Technology, 12, 617-632.

29. Mulligan, C., Yong, R. \& Gibbs, B. 2001. Remediation technologies for metal-contaminated soils and groundwater: an evaluation. Engineering geology, 60, 193-207.

30. Mulligan, C.N. 2009. Recent advances in the environmental applications of biosurfactants. Current Opinion in Colloid \& Interface Science, 14, 372-378.

31. Mulligan, C.N., Yong, R.N. \& Gibbs, B.F. 1999a. On the use of biosurfactants for the removal of heavy metals from oil-contaminated soil. Environmental Progress, 18, 50-54. 
32. Mulligan, C.N., Yong, R.N., Gibbs, B.F., James, S. \& Bennett, H. 1999b. Metal removal from contaminated soil and sediments by the biosurfactant surfactin. Environmental Science \& Technology, 33, 3812-3820.

33. Qixing, Z. 2002. Technological reforger and prospect of contaminated soil remediation. Technigues and Equipment for Enviro. Poll. Cont, 8, 009.

34. Razo, I., Carrizales, L., Castro, J., Díaz-Barriga, F. \& Monroy, M. 2004. Arsenic and heavy metal pollution of soil, water and sediments in a semi-arid climate mining area in Mexico. Water, Air, \& Soil Pollution, 152, 129-152.

35. Roy, D., Kommalapati, R., Mandava, S., Valsaraj, K. \& Constant, W. 1997. Soil washing potential of a natural surfactant. Environmental Science \& Technology, 31, 670-675.

36. Sarubbo, L., Rocha Jr, R., Luna, J., Rufino, R., Santos, V. \& Banat, I. 2015. Some aspects of heavy metals contamination remediation and role of biosurfactants. Chemistry and Ecology, 31, 707-723.

37. Sharma, R.K., Agrawal, M. \& Marshall, F. 2007. Heavy metal contamination of soil and vegetables in suburban areas of Varanasi, India. Ecotoxicology and Environmental Safety, 66, 258-266.

38. Shin, K.-H., Kim, K.-W. \& Ahn, Y. 2006. Use of biosurfactant to remediate phenanthrene-contaminated soil by the combined solubilization-biodegradation process. Journal of Hazardous Materials, 137, 1831-1837.

39. Soberón-Chávez, G. \& Maier, R.M. 2011. Biosurfactants: a general overview. Biosurfactants. Springer.

40. Soll, R. \& Blanco, F. 2001. Natural surfactant extract versus synthetic surfactant for neonatal respiratory distress syndrome. The Cochrane Library.
41. Venkatesh, N.M. \& Vedaraman, N. 2012. Remediation of soil contaminated with copper using rhamnolipids produced from Pseudomonas aeruginosa MTCC 2297 using waste frying rice bran oil. Annals of Microbiology, 62, 85-91.

42. Wang, S. \& Mulligan, C.N. 2004. An evaluation of surfactant foam technology in remediation of contaminated soil. Chemosphere, 57, 1079-1089.

43. Wei, B. \& Yang, L. 2010. A review of heavy metal contaminations in urban soils, urban road dusts and agricultural soils from China. Microchemical Journal, 94, 99-107.

44. Wuana, R., Okieimen, F. \& Imborvungu, J. 2010. Removal of heavy metals from a contaminated soil using organic chelating acids. International Journal of Environmental Science \& Technology, 7, 485-496.

45. Zeng, F., Ali, S., Zhang, H., Ouyang, Y., Qiu, B., Wu, F. \& Zhang, G. 2011. The influence of $\mathrm{pH}$ and organic matter content in paddy soil on heavy metal availability and their uptake by rice plants. Environmental Pollution, 159, 84-91.

46. Zhang, C., Valsaraj, K.T., Constant, W.D. \& Roy, D. 1998. Surfactant screening for soil washing: Comparison of foamability and biodegradability of a plant-based surfactant with commercial surfactants. Journal of Environmental Science \& Health Part A, 33, 1249-1273.

47. Zhou, W., Wang, X., Chen, C. \& Zhu, L. 2013. Enhanced soil washing of phenanthrene by a plantderived natural biosurfactant, Sapindus saponin. Colloids and Surfaces A: Physicochemical and Engineering Aspects, 425, 122-128.

48. Zou, Z., Qiu, R., Zhang, W., Dong, H., Zhao, Z., Zhang, T., Wei, X. \& Cai, X. 2009. The study of operating variables in soil washing with EDTA. Environmental Pollution, 157, 229-236. 